\title{
Consideration of reinforced concrete crushing through cohesive models
}

\section{Consideração do esmagamento no concreto armado através de modelos coesivos}

T. B. EVANGELHO a tiagoevangelho@yahoo.com.br

E. BITTENCOURT a eduardo.bittencourt@ufrgs.br

\begin{abstract}
In this work, the overlapping crack mode is considered. It permits the modeling of concrete crushing through cohesive surfaces, in a similar way used to simulate fracture. The material is considered in damage when the surfaces interpenetrate each other. Besides simplicity, the big advantage of the methodology is the fact that constitutive relations are independent of the material scale. A generalization is here introduced to consider mixed crushing. Exploratory applications are made considering super-reinforced beams. The effects of the height of the beams, compressive rebars and stirrups are investigated. A good fitting with experiments is obtained.
\end{abstract}

Keywords: reinforced concrete, crushing, cohesive models, finite elements.

\section{Resumo}

Neste trabalho é empregado o modelo de trincas sobrepostas, que permite modelar o comportamento em esmagamento do concreto através de superfícies coesivas, de forma similar à empregada na simulação de fraturas. O material entra em dano de compressão quando há interpenetração das superfícies. Além da simplicidade, a grande vantagem da metodologia é estar baseada em relações constitutivas independentes da escala do material. Uma generalização é introduzida de modo a considerar o modo misto de esmagamento. Aplicações exploratórias são realizadas considerando vigas super-armadas de concreto. Investigou-se o efeito da altura das vigas, das armaduras de compressão e dos estribos. Um bom ajuste com dados experimentais é obtido.

Palavras-chave: concreto armado, esmagamento, modelos coesivos, elementos finitos.

a Universidade Federal do Rio Grande do Sul, Departamento de Engenharia Civil, Escola de Engenharia, Porto Alegre, Brasil. 


\section{Introduction}

The post-peak behavior of concrete under compression has fundamental importance on ductility of it, modifying the ultimate behavior of reinforced concrete beams. The fact that post-peak stress-strain relations are strongly dependent on the scale [1] makes the objectivity of the analysis of such cases extremely doubtful. The strong localization of strains observed in the post-peak failure is another important characteristic. It indicates that the energy dissipation in this stage occurs in fact at internal surfaces of the material and not in volume [2].

Due to these two aspects, Carpinteri et al. [3,4] and Corrado [5] proposed a methodology to model concrete crushing using a methodology similar to the cohesive models used in Fracture Mechanics $[6,7]$. In the cohesive models, cracking is represented discretely by surfaces that separate each other symbolizing the crack opening. In the crushing model these surfaces overlap each other when there is compression. Such methodology is named "the overlapping crack model" by the authors and it is based on Fracture Mechanics principles. Then the constitutive law to represent the post-peak behavior of the concrete in compression is defined by a stress-displacement relation. The constitutive law is then not prone to objectivity problems, i.e. it is not dependent on the scale, as experimentally confirmed by van Vliet and van Mier [8] and by Jansen e Shah [9]. In the present work, the overlapping crack model [3-5] together with the cohesive crack model [7] are used in order to simulate completely the failure process of different reinforced concrete beams. Only super-reinforced beams are considered. In these cases, concrete is crushed in the final stages of the failure process. The overlapping crack model is here generalized in order to consider mixed mode fracture (shear effects), although such cases will not be considered in the experiments. In the chapter 2 is initially described the overlapping crack model considering only normal tractions and then modifications are introduced to consider mixed mode. In the chapter 3 , numerical simulations are done. Beams

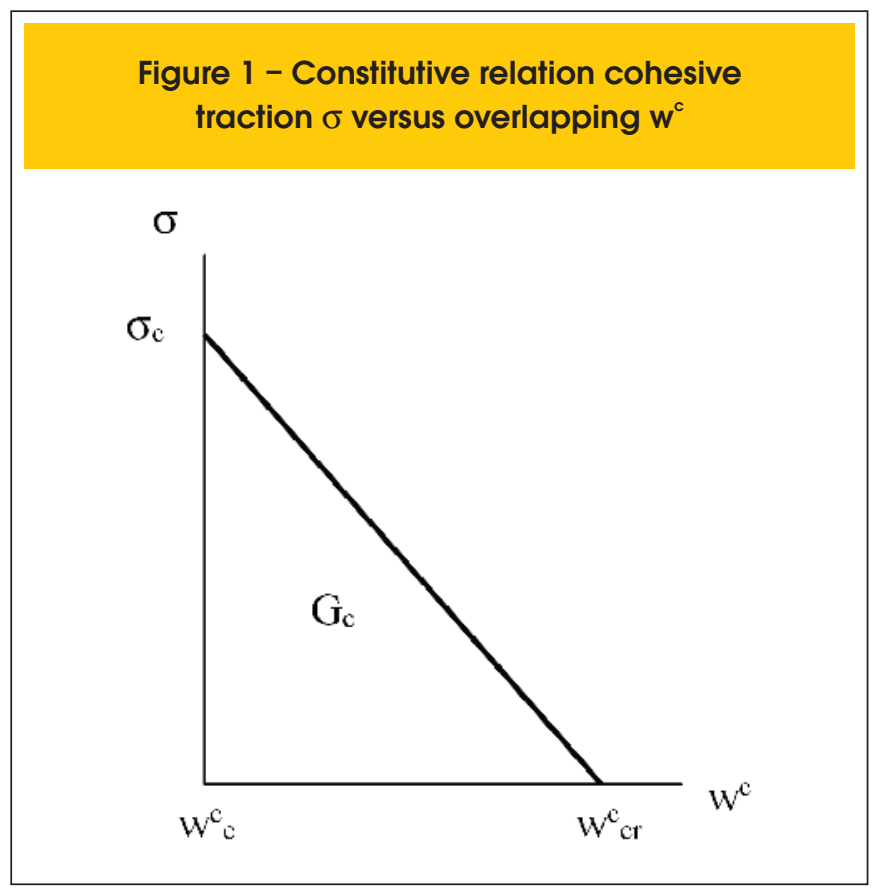

with different sizes and stirrup types are considered. The effect of compression rebars is also investigated. Final remarks are made in chapter 4

\section{The overlapping crack model}

In this chapter, the overlapping crack model is described for two situations. First, the case where the cohesive surface is under normal tractions only is considered and, second, a general situation is taken into account, where the surface is under normal and shear tractions. Implementation of the model in a finite element context is also described.

\subsection{Consideration of normal tractions}

Two internal surfaces of the body are considered where the separation between them is defined as $w$. If the surfaces open (cracking) the separation is positive and will be here identified by variable $w^{t}$. A traction $s$ is then created. As it opposes opening, it is called a cohesive traction $[6,7]$. If the surfaces overlap (crushing) the separation is negative and will be here identified by variable $w^{c}$. A traction $s$ is also created in this case, opposing the overlapping. The constitutive relation s versus $w^{c}$ is the crushing constitutive law. In the present work such relation is separated in two parts: the prepeak and the post-peak.

The pre-peak relation is elastic-linear and is valid for tractions smaller than compression strength $\left(\sigma_{c}\right)$. The overlap corresponding to this situation is identified by $w^{c}$ and must be minimal [10]. The pre-peak relation does not exist in the original overlap crack model. The post-peak relation is defined in Figure 1.

The area under the traction-overlap curve is designated crushing specific energy $\left(G_{c}\right)$, in analogy with the specific energy of fracture $\left(G_{f}\right)$, which is the area under the traction-opening curve. The overlapping model takes into account, in a simplified way, complex phenomena linked to crushing as fragmentation and propagation of micro-cracks in shear. Then $G$ can be interpreted as the sum of the energy dissipated by micro-cracks during crushing plus friction effects [11]. As a consequence, $G_{c}$ is, in general, two or three orders of magnitude greater than $G_{f}$. For plain concrete with $s_{c}$ ranging from 20 to $90 \mathrm{MPa}$, corresponding $G_{c}$ ranges from 30 to 58 $\mathrm{N} / \mathrm{mm}[12,13]$. However, the most basic aspect to be considered here is that $G_{c}$ as well as the traction-overlap relation are concrete properties and are independent of the scale.

Suzuki et al. [13] established models to take into account the confinement effect due to stirrups. The authors determined relations of $G_{c}$ with the steel yield stress used in stirrups as well as with the volume fraction of stirrups. The presence of stirrups increases considerably $G_{c}$ and critical overlap $w_{c r}^{c}$. For instance, values in the order of up to $500 \mathrm{~N} / \mathrm{mm}$ are reported to $G_{c}$ in case of a high volume fraction of stirrups.

\subsection{Mixed mode considerations}

The original overlapping crack model [3-5] considers that cohesive surface is subjected to normal tractions only. In this work a generalization is proposed in order to include the effect of shear tractions $\tau$.

Shear effects are here considered irrelevant until a limit defined by the Mohr-Coulomb relation is attained. This condition can be 


\section{Figure 2 - Elastic limits of the cohesive elements in space $\sigma$ versus $\tau$}

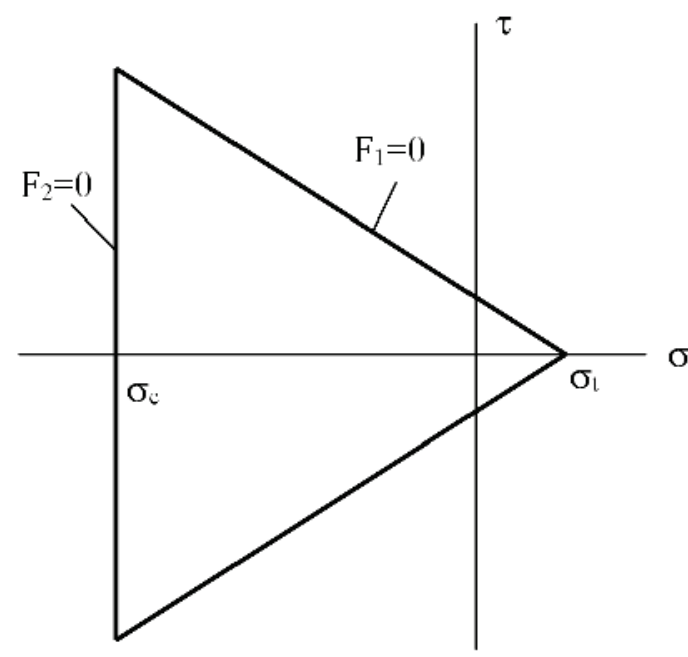

seen in Figure 2. $F_{1}=0$ represents the traction limit according to the Mohr-Coulomb failure criterion, while $F_{2}=0$ represents the traction limit linked to crushing. $F_{1}$ and $F_{2}$ are defined below, where $\phi$ is the concrete friction angle and $\sigma_{t}$ its tensile strength.

$$
\mathrm{F}_{1}=|\tau|-\left(\sigma-\sigma_{\mathrm{t}}\right) \tan \phi ; \quad \mathrm{F}_{2}=\sigma-\sigma_{\mathrm{c}}
$$

If $F_{1}$ and $F_{2}$ are smaller than zero, material behavior is elastic. Graphically this situation corresponds to the internal region of the triangle shown in Figure 2. Tractions outside the triangle $\left(F_{1}\right.$ and/or $\left.F_{2}>0\right)$ are forbidden and must return to the surface. In this return process irreversible (or "plastic") deformations are created, which are the responsible to damage the material. For instance, if $F_{2}>0$, the return process creates irreversible values of $w^{c}$ that ultimately will decrease compression strength

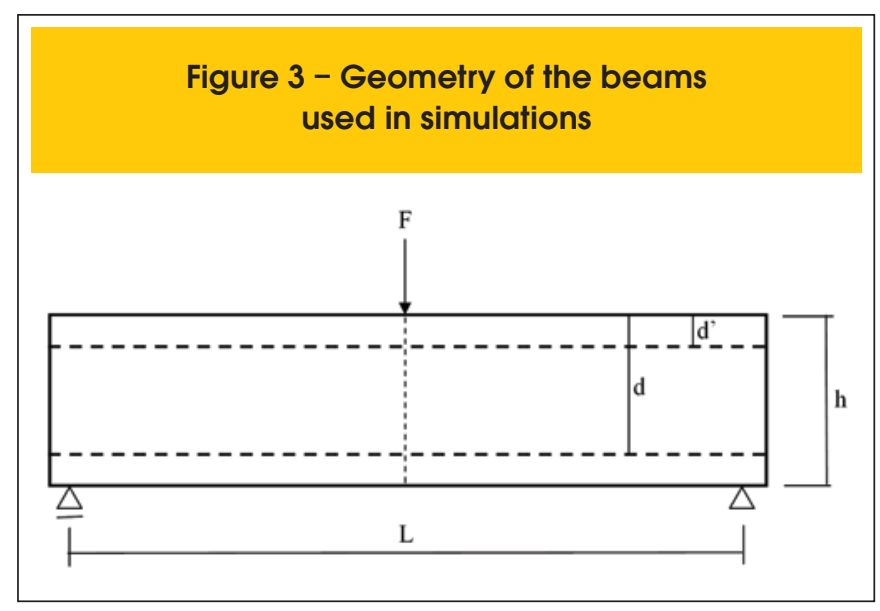

$\sigma_{c}$, according to relation shown in Figure 1. Graphically this situation can be seen as the line $\mathrm{F}_{2}=0$ moving toward the right, in Figure 2. The process is completed when $\sigma_{c}=0$, i.e. the material is completely damaged, without any strength. Details regarding the return process can be find in Evangelho [10] and Lens et al. [7].

\subsection{Implementation in finite elements}

In order to implement the methodology in a finite element context, internal surfaces are created using duplicated nodes in the mesh. Then the link between elements is done by cohesive tractions and not by the connectivity as in a standard methodology.

Once the surfaces are defined, opening and overlapping can be calculated and then cohesive tractions, following the procedures described above. Nodal forces can be obtained from the spatial integration of tractions. These forces are added to the global assemble of forces computed by standard finite element procedures. All non-linearity is confined to cohesive surfaces. The explanation for such restriction is based on the damage nature of the concrete, which is confined at surfaces, the volume remaining elastic-linear. Balance equations are satisfied through the use of the NewtonRaphson solution method. The volumetric finite element used is a linear four-node isoparametric with Lagrangean interpolation function.

\section{Numerical experimentation}

In this chapter, isostatic three-point beams of reinforced concrete are tested. Two points support the beams at the borders and are symmetrically loaded at the center, as seen in Figure 3 . Plane strain state is considered. In the numerical modeling, rebars are replaced by a layer of steel with an equivalent height. This height is obtained by dividing the total cross section area of the rebars by the thickness of the beam. The equivalent layer is placed in the same position of the rebars.

The dotted horizontal line at the bottom of the beam in Figure 3 indicates the position of the tensile rebars and the dotted horizontal line at the top the position of the compression rebars. Based on physical observations, it is assumed that crushing process is totally localized at the central transversal section. Cracking is also considered localized at the same section, so all cohesive elements are placed in a central line, perpendicular to the length of the beam, as indicated by the dotted vertical line in Figure 3.

Four different beams are numerically simulated in this work and compared to experimental results of Burns and Siess [14]. Table 1 gives a description of the analyzed beams (denomination follows reference [14]).

Table 1 - Characteristic of the tested beams (14)

\begin{tabular}{ccccc} 
Beam & $\begin{array}{c}\sigma_{\mathrm{c}} \\
(\mathrm{MPa})\end{array}$ & $\begin{array}{c}\sigma_{\text {osc }} \\
(\mathrm{MPa})\end{array}$ & $\mathrm{h}(\mathrm{mm})$ & $\mathrm{d}(\mathrm{mm})$ \\
$\mathrm{J} 1$ & 34 & 330 & 305 & 255 \\
$\mathrm{~J} 2$ & 28 & 330 & 305 & 255 \\
$\mathrm{~J} 10 / \mathrm{J} 19$ & 25 & 310 & 405 & 355 \\
\hline
\end{tabular}


$\sigma_{\text {esc }}^{\circ}$ is the initial yield stress of the rebars. In all cases the same tensile rebars are used: two bars with $25,4 \mathrm{~mm}$ diameter. J2 beam is the only with compression rebars. They are two with $19 \mathrm{~mm}$ diameter and placed at d' $=50 \mathrm{~mm}$ (Figure 3 ). The steel is considered elastic-plastic with non-linear hardening defined by equation 2 :

$$
\sigma_{\mathrm{esc}}=\sigma_{\text {esc }}^{0}+\left(\sigma_{\text {esc }}^{\infty}-\sigma_{\text {esc }}^{0}\right)\left[1-\exp \left(-\mathrm{k} \varepsilon^{\mathrm{pl}}\right)\right]
$$

where $\varepsilon^{p l}$ is the plastic strain. For the constants $\sigma_{\text {esc }}^{\infty}$ and $k$ the values $500 \mathrm{MPa}$ and 2.5 are adopted, respectively, in order to adjust the stress-strain relation for the steel.

Except for case J19, all beams have stirrups with diameter equal to $9.5 \mathrm{~mm}$. In case J19 stirrups have a diameter equal to $6.3 \mathrm{~mm}$. In all cases spacing is equal to $150 \mathrm{~mm}$.

Concrete-rebar bonding is modeled according the Code Model 90 [15]. Due to the presence of stirrups the confined condition was used. The length $L$ of the beams is always the same and is equal to 3650 $\mathrm{mm}$, as well as the thickness, equal to $200 \mathrm{~mm}$.

To consider cracking, tensile strength is defined as $\sigma_{t}=0.3\left(\sigma_{\partial}\right)^{2 / 3}$ and $G_{f}=0.09 \mathrm{~N} / \mathrm{mm}$ in all cases.

In Figure 4 numerical results of load/deflection for case $\mathrm{J} 1$ are shown. Experimental results presented by Burns e Siess [14] are also shown. These authors describe the sequence of events in the experimentation as follows: elastic-linear behavior occurs only at the beginning of the test, with cracking initiating for a very low level of loading. For a loading level around $80 \mathrm{kN}$, the slope of the load/ deflection curve decreases substantially. This change is linked to the onset of steel yielding. Afterwards the concrete crushing begins, decreasing further the curve slope, which ultimately becomes negative. The present model captures all this sequence of events. When crushing is not considered, peak loading is over-estimated by more than $10 \%$, as seen in Figure 4 . On the other side, the crushing energy has an effect only on the ductility of the beam. For a critical overlap $\left(W_{c r}^{c}\right)$ equal to $5 \mathrm{~mm}\left(G_{c}=85 \mathrm{~N} / \mathrm{mm}\right)$ the maximal

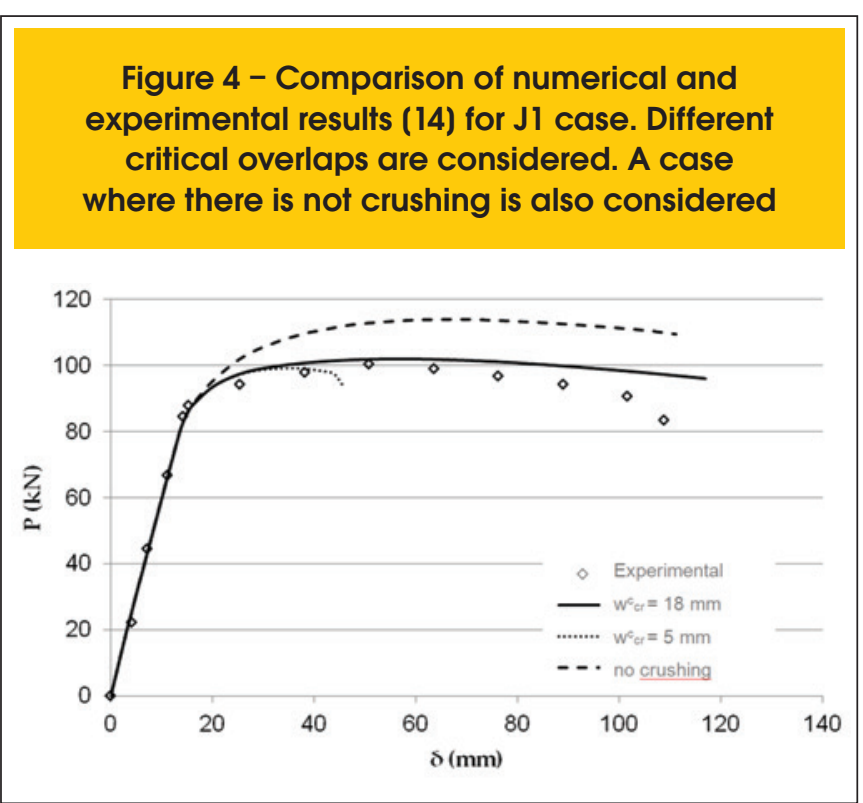

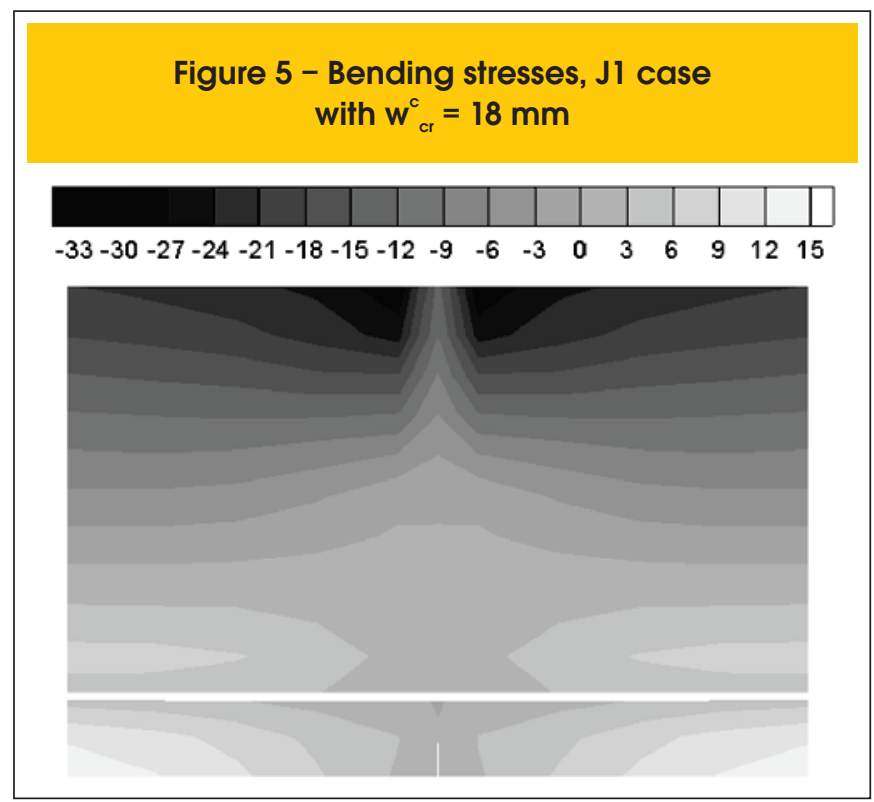

deflection of the beam is not larger than $50 \mathrm{~mm}$. For $w_{c r}^{c}=18 \mathrm{~mm}$ $\left(G_{c}=306 \mathrm{~N} / \mathrm{mm}\right)$ the ductility is similar to ductility observed in experiments, with a maximal deflection equal to $120 \mathrm{~mm}$.

Figure 5 shows the distribution of bending stresses for the same case $\mathrm{J} 1$, in the central region of the beam (case $w_{c r}^{c}=18 \mathrm{~mm}$ ). In the compressed zone (top of the beam) it is observed that stresses are never greater than compressive strength. At the very center of the beam stresses are smaller due to crushing and material damage, as expected. Those observations indicate that the use of only one line of cohesive elements is enough to capture crushing effects.

On the other side, in the traction zone (bottom of the beam) it is observed that bending stresses are greater than the tensile strength, estimated here to be around $3 \mathrm{MPa}$. This observation indicates that the use of only one cohesive line is not enough to capture completely the process of cracking in reinforced concrete.

In Figure 6, J1 and J10 beams are compared. The fundamental difference between them is the larger height of the case J10. It

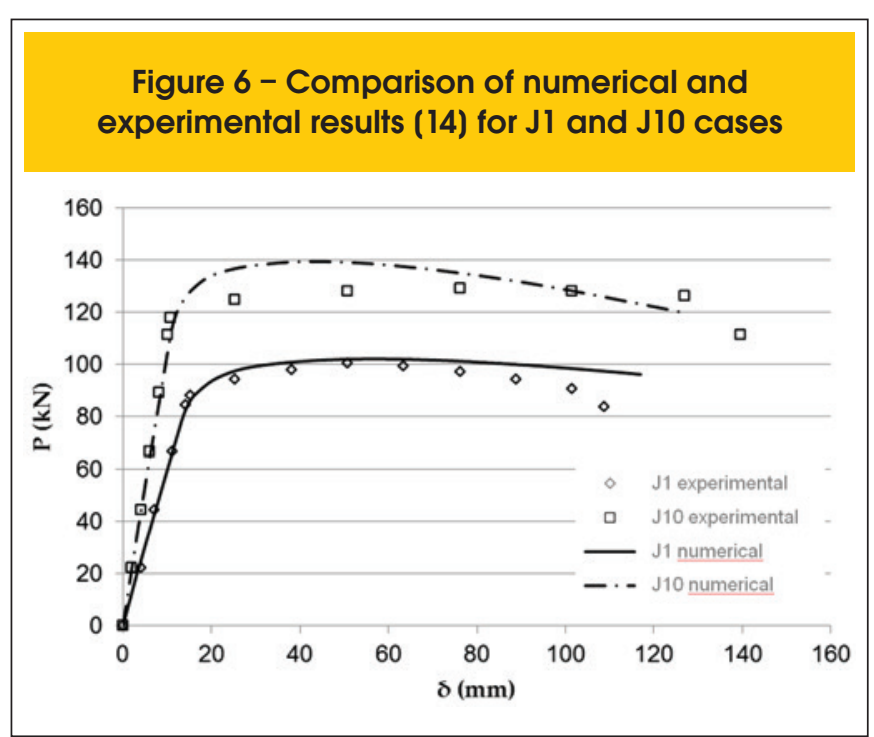


can be observed a good fit with experiments, as before. In case J1 $W_{c r}^{c}=18 \mathrm{~mm}$ and in case $\mathrm{J} 10 \mathrm{~W}_{c r}^{c}=22 \mathrm{~mm}$.

In the simulations made in the present work, cases with larger height present the trend to overestimate the load for steel yielding. According to Carpinteri et al. [16], this loading is strongly influenced by concrete cracking and higher beams tend to suffer more cracking. As the models used in the present work have a poor representation of cracking (Figure 5), this can be an explanation for the difficulties observed in higher beams.

The effect of compression rebars was also investigated. Numerical results are compared with experiments in cases $\mathrm{J} 1$ and $\mathrm{J} 2$ in Figure 7 (case $\mathrm{J} 2$ has compression rebars while case $\mathrm{J} 1$ does not, as described before). In both cases the same critical overlap (18 $\mathrm{mm}$ ) is used.

According to Carpinteri et al. [16], a substantial increase in the ultimate deformation of the beam is expected when compression rebars are introduced. This characteristic is captured by the present model, as seen in Figure 7, where the deformation of $\mathrm{J} 2$ beam is approximately three times as much the deformation of $\mathrm{J} 1$ beam. Still according to these authors, cracking has small influence in the ultimate behavior of this kind of beam, which is driven by crushing phenomena. As already commented, cracking has influence on the onset of steel yielding, or the beginning of the plateau of the load/ deflection curve, exactly where the discrepancy with experiments is larger.

Transversal rebars (stirrups) are used basically to resist shear effects. In the cases analyzed here, they are considered to be rectangular. A decrease in the volume fraction of stirrups leads to a smaller critical overlap [12], case of the J19 beam when compared to others. In Figure 8, the behavior of $\mathrm{J} 19$ beam is compared with $\mathrm{J} 10$ beam. In the first $w_{c r}=13,75 \mathrm{~mm}$ and in the latter $w_{c r}=22 \mathrm{~mm}$ in accordance with the correspondent volume of stirrups.

It can be concluded, from numerical and experimental results, that the increase in the density of stirrups implies an increase in the beam deflection, without a noticeable increase in the maximal load supported. The reason is that stirrups basically increase ductility via concrete confinement, resulting a greater ultimate deflection.

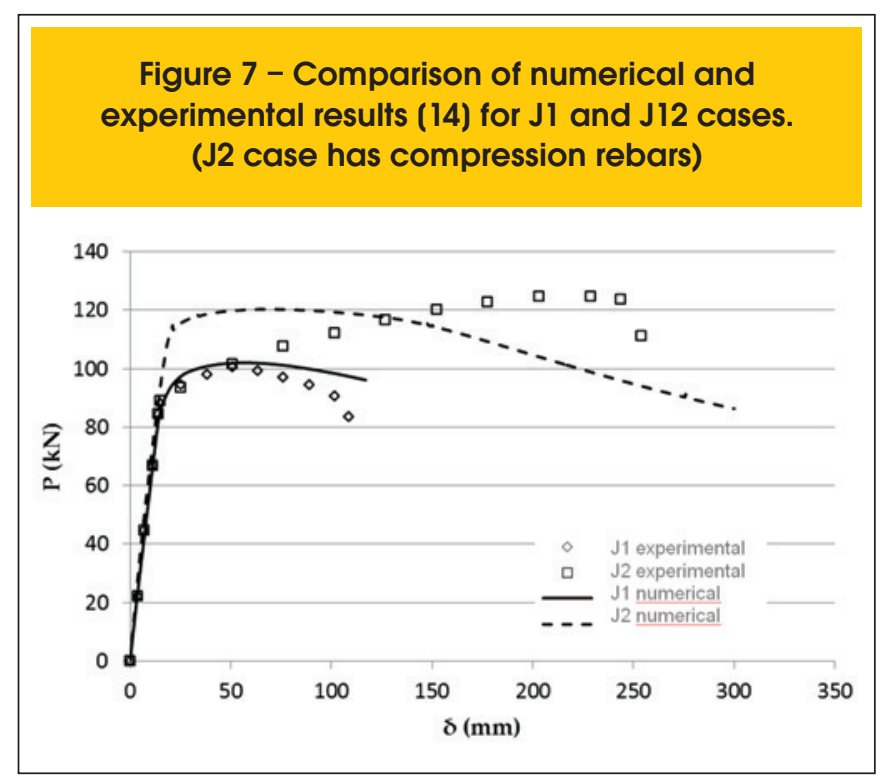

\section{Final remarks}

In this work the overlapping crack model was used. The model permits to consider concrete crushing through traction/overlap constitutive laws, where scale effects are minimal. An exploratory study of the methodology was done in order to access its viability. Three different three-point beams were considered. Numerical results were compared with experiments [14] with the following conclusions:

- Damage in the reinforced concrete occurs in the following order: cracking, steel yielding and concrete crushing. The model presented in this work (cohesive models for cracking and crushing, coupled with a discrete model for rebars and the bonding concrete/rebar) was able to capture all these phases in a relatively precise way.

- Concretes with a higher crushing energy have a more ductile behavior. This energy increases substantially with the density of stirrups. In the case of plain concrete it is a material property.

- The methodology is able to capture automatically the effects of compression rebars, which increase considerably the ductility of the beam.

- The methodology is able to capture qualitatively the effects of stirrups on ductility.

- The methodology can be easily implemented in any non-linear finite element code.

The main goal of this work was to investigate the viability of the methodology. A more detailed study of the relations between crushing energy and density of stirrups would be very helpful. Another interesting study would be an investigation of the shear effects on crushing behavior. Such study would be fundamental to have a better understanding of rebars pull-out.

\section{Acknowledgements}

The authors thank CAPES and CNPq for the financial support.

\section{References}

[01] Indelicato, E. and Paggi M. Specimen shape and the problem of contact in the assessment of concrete

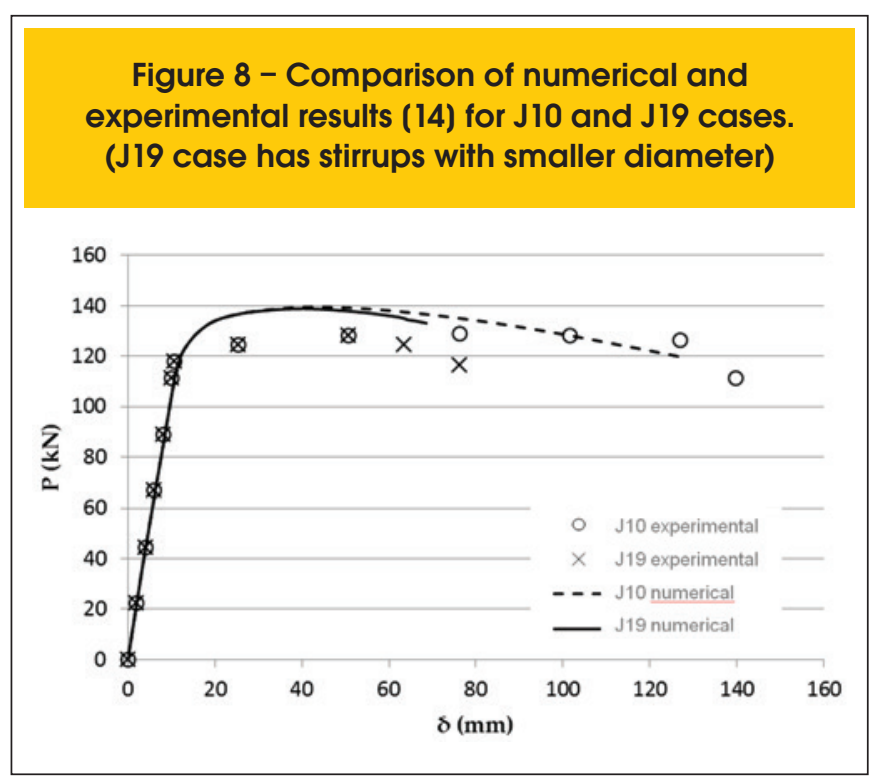


compressive strength. Materials and Structures, v.41, n.2, 2008; p. 431-441.

[02] Van Mier, J. G. M. Strain softening of concrete under multiaxial compression, Eindhoven, 1984, Tese (doutorado) Eindhoven University of Technology, The Netherland.

[03] Carpinteri, A., Corrado, M., Paggi, M. and Mancini,G. Cohesive versus overlapping crack model for a size effect analysis of RC members in bending. In: $6^{\text {th }}$ International FraMCoS Conference, Catalunia, 2007, Proceedings, v.2, p.655-63.

[04] Carpinteri, A., Corrado, M., Paggi, M. and Mancini,G. A numerical approach to modelling size effects on the flexural ductility of RC beams. Rilem Materials and Structures. doi: 10 1617/s11527-00809454-y.

[05] Corrado, M., Effetti di scala sulla capacita di rotazione plastica di travi in calcestruzzo armato, Torino, 2007, Tese (doutorado) - Politecnico di Torino, Itália.

[06] Hillerborg, A Moderer, M. and Peterson, P. E. Analysis of crack formation and crack growth in concrete by means of fracture mechanics and finite elements. Cement and Concrete Research, v.6, n.6, 1976, p.773-782.

[07] Lens, L. N.,.Bittencourt, E. and d'Avila, V. M. R. Constitutive models for cohesive zones in mixed-mode fracture of plain concrete. Engineering Fracture Mechanics, v.76, 2009, p.2281-2297.

[08] van Vliet, $\mathrm{M}$ and van Mier, J. Experimental investigation of concrete fracture under uniaxial compression. Mechanics of cohesive-frictional material, v.1, n.1, 1996, p.115-127.

[09] Jansen, D. C. and Shah, S. P. Effect of length on compressive strain softening of concrete. Journal of Engineering Mechanics, v.123, n.1, 1997, p.25-35.

[10] Evangelho, T. B. Consideração do esmagamento do concreto através do modelo de trincas sobrepostas. Porto Alegre, 2013, Dissertação (mestrado) - Universidade Federal do Rio Grande do Sul.

[11] Carpinteri, A., Ciola, F. and Pugno, N. Boundary element method for the strain-softening response of quasi-brittle materials in compression. Computers and Structures, v.79, n.4, 2001, p.389-401.

[12] Carpinteri, A., Corrado, M., Mancini, G. and Paggi, M. The overlapping crack model for uniaxial and eccentric concrete compression tests. Magazine of Concrete Research, v.61, n.9, 2009, p.745-757.

[13] Suzuki, M., Akiyama, M., Matsuzaki, H. and Dang, T. H. Concentric loading test of RC columns with normal and high strength materials and averaged stress-strain model for confined concrete considering compressive fracture energy. In: $2^{\text {nd }}$ International Congress Federation Internationale du Beton, Naples, 2006, Proceedings, session 3, p.1-10.

[14] Burns, N.H. and Siess, C.P. Plastic hinging in reinforced concrete. Journal of Structural Division, ASCE, v.92, 1966, p. 45-61.

[15] COMITÉ EURO-INTERNATIONAL DU BÉTON. CEB-FIP Model Code 1990. Bulletin d'Information, Lausanne, n. 213/214, mar. 1993.

[16] Carpinteri, A., Corrado, M. and Paggi, M. An integrated cohesive/overlapping crack model for the analysis of flexural cracking and crushing in RC beams. International Journal of Fracture, v.161, 2010, p.161-173. 